\title{
Taking Care: Criticality and Reflexivity in the Context of Social Work Registration
}

\section{Gloria Kirwan ${ }^{1, *}$ and Brian Melaugh ${ }^{2}$}

\footnotetext{
${ }^{1}$ School of Social Work and Social Policy, Trinity College Dublin, Dublin 2, Republic of Ireland ${ }^{2}$ Department of Applied Social Studies, National University of Ireland, Maynooth, County Kildare, Republic of Ireland

*Correspondence to Gloria Kirwan, School of Social Work and Social Policy, Arts Bldg, Trinity College Dublin, Dublin 2, Republic of Ireland. E-mail: kirwangm@tcd.ie
}

\begin{abstract}
Prompted by the introduction of statutory social work registration into the Republic of Ireland, the authors consider the assumptions that attach to regulation, including the promise of greater public protection vis-à-vis the management of misconduct issues by social work regulators. They ponder the paradoxical implications for the future of social work if, notwithstanding the arguments in favour of registration, social work fails to theorise and critically reflect on the prevention, interpretation and management of professional misconduct.
\end{abstract}

Keywords: professional registration, fitness to practise, professional misconduct, reflexivity

Accepted: December 2014

\section{Introduction}

The number of countries where social workers are subject to professional registration is on the rise. The Republic of Ireland, where both authors are based, became a recent addition to the list when it established under law (Health and Social Care Professionals Act, 2005) a statutory Social Work Register in 2011 (CORU, 2011). It thus joined a growing list of jurisdictions including England, Wales, Scotland, Northern Ireland, Canada, the USA and New Zealand where social work registers are already up and running.

This development in the Republic of Ireland prompted the authors to become better informed on misconduct issues which can arise within the 
social work profession and how they are dealt with by registration bodies. In this comment paper, we share observations arising from our exploration of this topic which highlight a need for stronger theorisation and reflection on how misconduct is conceptualised, why misconduct occurs and if social work regulation is a sufficient response to it. In particular, we query how, if at all, the increasingly intense regulatory gaze on misconduct delivers on its promise of higher standards in professional practice.

\section{The rise of regulation}

The introduction of the Social Work Register in the Republic of Ireland can be located within a broader, international promotion of social regulation in health and social services. Distinct from economic regulation, social regulation has emerged as part of a wider strategy of public service governance which aims to ensure that services are delivered in a safe and socially acceptable manner (Koornneef, 2008). Koornneef (2008, p. 5) quotes Selznick's (1985, p. 363) definition of regulation as 'sustained and focused control exercised by a public agency over activities which are valued by a community'. In this light, the primary purpose of professional registration is to ensure that the public is protected from harmful or socially unacceptable practices on the part of service providers, in this instance, social workers. Additional drivers underpinning social regulation include public expectations of quality service provision, the growing focus on risk avoidance within society and the increasingly embedded political expectations regarding service provider accountability and clinical governance. Therefore, the discourse of regulation links benefits flowing from its implementation, not only to its primary objective which is protection of the public, but to wider concepts such as social betterment, the greater good and what Walshe (2009) refers to as 'sunshine' regulation, wherein the act of regulation becomes a good in itself by contributing information on how services can be improved. In effect, while regulation is seen as one means to underpinning safe and accountable service delivery, it is also about ensuring that unsafe practice is addressed and, where possible, eliminated. In such a context, attention to the issue of professional misconduct is heightened and regulatory authorities are imprinted with the social mandate to oversee a safe service environment and with the authority to intervene when necessary.

\section{Social work as a moral profession}

For many decades, the social work profession has devoted considerable effort to articulating and reflecting on the moral basis of social work practice. Recent examples in the literature include consideration of moral character (Holmström, 2014; Clark, 2006), professional integrity (Banks, 2010), 
suitability for practice (Currer, 2009; Dillon, 2007) and ethical awareness (Nathanson et al., 2011). Prior to the introduction of statutory social work registers in any jurisdiction, our literature search revealed that the profession had a recorded history of responding to cases of misconduct and ethical violations. For example, Strom-Gottfried $(2003,1999)$ and McCann and Cutler (1979) report on their analyses of cases adjudicated on professional associations. Boland-Prom (2009) refers to research carried out by the National Association of Social Workers (1995) on a decade of its own adjudications. Such studies provide evidence that the profession has been concerned over previous decades to address the issue of professional misconduct in the relatively small number of cases in which it has come to light.

\section{Professional misconduct in social work}

It is the current norm for social work registration bodies to publish annual statistical information on the numbers and types of fitness to practise cases with which they deal. Summary accounts of individual cases which go to a full hearing are also routinely reported by registration bodies. From our literature search, we discovered that an extensive amount of documentary information of this type is currently accessible within the public domain concerning cases of social work fitness to practise which include complaints of misconduct, lack of competence or both. It comes mainly in the form of raw data, namely reports of individual cases which have come to the attention of regulatory authorities.

Some commentary has emerged from within the social work profession on how the information emerging from the regulatory authorities on the issue of misconduct can be theorised and critiqued (see e.g. Furness, 2013; McLaughlin, 2007). An interesting study has also been reported by McKenna, Day and Munro (2012) who examined a set of cases referred to the Independent Safeguarding Authority. But there is room for far more theorisation on the issue of safe/unsafe professional practice and it is this theoretical gap in the literature which this comment paper seeks to highlight.

To progress our own understanding of misconduct in the profession, we carried out a standardised review of seventy-two fitness to practise hearings from 2011, sourced from the websites of the General Social Care Council, the Scottish Social Care Council, the Care Council of Wales and the Northern Ireland Social Care Council. We adopted a qualitative orientation and thematically analysed our sample by reading through the details of each case, devising and revising a schedule of themes which emerged from the reports and by cross-checking for similarities and differences in our observations.

It is not possible in the space provided here to provide a detailed report of our findings. Instead, we outline here the thematic signposts which we found helped us make sense (to some degree) of the data we examined. Two main categories of misconduct emerged from our analysis. The first 
concerned cases in which the registrant was found to have engaged in acts which were criminal, abusive or inappropriate in nature. The types of misconduct involved in this category ranged from common assault to drug importation, and involved activities which may or may not have been directly associated with the social worker's job. This category also included cases where the registrant was found to have engaged in conduct which we believe most social workers would find unequivocally incompatible with the expected standards of professional behaviour but which had no reported involvement of the criminal justice system. These cases included behaviour such as relationship boundary violations and examples included sending inappropriate or sexually suggestive text/e-mail messages to service users. In the majority of misconduct cases in this first category, the registrant received a severe sanction such as suspension or removal from the Social Work Register.

In the second main category, we found cases relating to issues which fitted more with a description of poor professional judgement or poor work performance. This category included cases where the registrants failed to properly investigate reports of risk to vulnerable people, or keep proper records of such assessments. It also included situations in which registrants failed to carry out the instructions of their line manager, leaving or potentially leaving individuals in dangerous situations. Failure to act within an appropriate time frame to safeguard others, closing cases when concerns remained active or failing to share information with relevant colleagues also featured in this category, as did failure to carry out required home visits. This category left us with questions about the organisational context within which the cases arose. We found the fitness to practise hearing reports usually provided sufficient information for us to understand the nature of the incidents which led to the hearing but gave sparse insight into the organisational context, positive or negative, within which they took place. We wondered about issues such as caseload size, supervision and organisational culture, and other constraints that may have surrounded these individual cases. We thought about the often hidden burden for teams of trying to cover the work of absent colleagues or unfilled posts (such as that highlighted by Jack and Donnellan (2010)) and whether such contributing factors had arisen, to even a small degree, in any of the cases. We would like to see more detail included in the summary reports of these cases regarding the organisational context within which these cases occurred, including details about clinical or safety governance, quality control systems and information on what avenues were available to these registrants to raise concerns about their ability (or not) to properly carry out their duties. Because we relied on summary reports of hearings, it was not possible for us to assess the extent to which organisational factors were queried or taken into account by the adjudicating committees which heard the individual cases and we stress that we are not in any regard finding fault with the quality of adjudication in these cases. However, we make the point that there is a consistent absence of this type of detail in the 
published reports of upheld misconduct cases and we concur with the call by Furness (2013) for more detailed information to be routinely reported.

As part of our analysis, we also attempted to assign a measure of seriousness to the cases we examined. We interpreted seriousness within a set of dimensions as follows:

(1) The level of abuse of power that the registrant was found to have engaged in.

(2) The extent or breadth of the misconduct, namely how many incidents and over what period of time.

(3) The level of insight on the part of the registrant, namely how aware was the registrant of the impact of their actions? Related to this is the question of whether or not concerns had been formally raised at any stage with the registrant about their conduct in the context of supervision or management communications, such as verbal or formal warnings.

(4) The involvement or not of the criminal justice system and whether the social worker has been criminally charged or convicted of behaviour related to the act of professional misconduct; this last dimension overlaps with the earlier classification of misconduct that we employed.

These dimensions of seriousness were sometimes clearly visible and noted in the individual case reports, but not in all. We found it difficult to apply a measure of seriousness to each case, as these dimensions did not always work out neatly in their application to any particular case. For example, a minor issue of misconduct, because it is carried out a number of times, is not necessarily greater than one act of major misconduct. While it was challenging to apply seriousness as an interpretative measure across all the cases within our analysis, we think this is a measure that could be revised and refined in future research on this issue.

Despite the challenges of using it as an interpretative concept, we concluded that seriousness is related not only to the type of misconduct, but also to the consequences for and the experience of the person(s) who is the victim of the misconduct. We noted that, in some case summaries, the likely impact on others of the acts of misconduct was factored into the decisions of the adjudicating committees but we found it quite challenging, due to lack of reported detail, to analyse how the concept of victim impact was applied across the decisions of different committees. We thought it ironic, given the primary raison d'être of regulation as protection of the public, that the reported judgements of adjudication committees showed varying levels of explicit attention to the impact of registrant misconduct on service users. There was no regular use, at least that we could identify from the case reports, of Victim Impact Reports. We speculated about the value of including routinely some form of assessment of victim impact in the process of adjudication of professional misconduct as a way of better aligning the adjudication of individual cases with the core regulatory aim of the protection of the public. 
Our study suffered other limitations related to its size in that we are not able to state with certainty whether certain fields of social work practice feature more often than others in reported cases of misconduct, or whether particular practitioner characteristics such as gender, age or length of service were of any significance (our figures were too small-scale to allow for definitive statements on such issues). As with the other issues we have raised, we hope to see further study on these factors.

\section{Discussion}

The setting-up of the Social Work Register represents a landmark in Ireland regarding public accountability and independent oversight of the social work profession in this jurisdiction. We use this landmark junction in time to ask what evidence there is, from jurisdictions where regulation is already operational, that social work practice has been improved as a result of a regulatory gaze. As we have outlined, our literature review found only a few examples of published debate or research on the interaction between professional regulation and the management of professional misconduct and equally little analysis on the extent to which regulation of this kind leads to a better profession.

One writer, Dickens (2010, p. 149), attempting to deconstruct the implications of professional regulation, identifies two paradoxes of regulation. The first concerns the aim of improved standards of care that regulation is supposed to ensure but which may be jeopardised, at least potentially, by the bureaucratisation that attaches to or is incubated within regulated environments. His second paradox concerns the issues of professional autonomy and creativity in the context of increased rules, such as codes of practice, ethics and conduct. We were drawn to the logic of the argument that the more rules there are to uphold, the more 'boxed in' social workers may become in how they respond to service users' needs and consequently their ability to intervene creatively in people's lives may be confined, diluted or reduced. It follows from this viewpoint that, when social workers are held more accountable, they may become more concerned to closely and demonstrably follow policies and procedures, and as a corollary become less likely to respond flexibly to the particular needs of individual service users, groups or communities. It is ironic that public expectations of what social workers can achieve may increase and expand with the introduction of professional regulation at just the same time as the ability to respond creatively on the part of social workers becomes constricted. We think these possible paradoxes deserve increased debate and research attention.

In exploring these paradoxes, and critically reflecting on our own smallscale analysis of a sample of cases, we identify a possible third paradox which suggests that the current systems in place to address individual cases of misconduct, simply because of their very existence, draw attention away 
from a more macro-located analysis of misconduct within the profession. We speculate that, despite the resources now devoted to surveillance of individual social workers, more general measures aimed at the prevention of professional misconduct are less evident. We found little evidence in our literature exploration to indicate that the profession has moved to make changes on foot of the lessons learned from the misconduct cases appearing in the reports of regulatory bodies. In fact, there is little evidence that the profession has spent much effort identifying what those lessons might be. We suggest that it is valid to ask what social work is doing in response to the (admittedly low) level of reported misconduct within the profession. Or, even at a very fundamental level, what sense does the profession make of misconduct within its ranks and how, as a professional group, are social workers theorising and reflecting on this issue?

We acknowledge that all of the regulatory systems that we have looked at encompass processes and mechanisms for managing allegations of misconduct against social workers which aim to ensure that service users are protected from social workers who present a risk of harm and that, equally, social workers are protected against malicious complaints. The Council for Health Care Regulatory Excellence (2009) outlines the principles of regulation which guide the regulator to conduct assessments of complaints in a 'transparent', 'accountable', 'proportionate' and 'agile' manner and to ensure that sanctions imposed by it are targeted and consistent. When sanctions against social workers are imposed by registration bodies, this is usually done in order to protect the public from further acts of misconduct or to send a message to the individual practitioner and the wider profession that the registration body views their behaviour in a serious light and sanctions are generally considered a protective rather than a punitive measure. Adherence to these principles of regulation is necessary for ensuring that both registrants and the public have confidence in the system of regulation itself.

But we ask is a safe adjudication system enough? Should we regard case hearings as the end point of the process of misconduct management and prevention or are we missing a vital final step which concerns itself with identifying the contributing factors across sets of misconduct cases so that the profession can set out to understand and respond to the factors that give rise to or contribute to misconduct in the first place? We see the need for more attention to interpretation of not just the misconduct itself, but how it arises, and how it is theorised and managed.

We are not resistant to other possible explanations for the lack of research or theoretical attention to social work misconduct by the profession. It is possible that the lack of such research reflects a concern within the profession about the increased pressure on individual practitioners to fix the ills of society in lieu of organisational or societal accountability for weaknesses in social provision. The emergence of regulatory systems can be located, arguably, within a broader neo-liberal shift (van Heugten, 2011) which 
distances organisations and society away from collective responsibility for the experience of the individual, particularly individuals located in marginalised or impoverished situations. The dilution of organisational or societal accountability for the day-to-day enactment of fiscal and social policies leaves front line workers fully accountable for the management of unmet needs and heightened social tension. We hope that, in the development of our knowledge on how and why misconduct arises in case-by-case interactions, this broader socio-political context will not be forgotten or overlooked.

When we initially set out to inform ourselves on the types of misconduct occurring within social work and the circumstances associated with it, we anticipated conducting a straightforward literature review. Quickly, it was clear that studies of this issue, while some do exist, are few in number. We hope that, by bringing a focus to this issue here, it will stimulate a more developed and sophisticated consideration of this topic. We agree with Walshe (2007) that theory-driven examination of such processes may be useful in building our knowledge. Walshe (2007, p. 58) advocates a researcher stance which sets out to establish findings which have 'theoretical rather than empirical generalizability' and, in a context where we are also trying to learn about an issue which transcends geographical borders, we think this is perhaps a better way to frame further research on the issue of professional misconduct in regulatory contexts.

We write this critical commentary not because we think that misconduct can be eradicated for good, but instead because we now see that arriving at any understanding of why misconduct occurs and how best it should be addressed is a complex and nuanced task and something which must be continuously examined and interrogated from many perspectives if we are to be assured that the large resources devoted to current systems of regulation are worth the outlay. It is clear that each case we examined arose within a unique set of circumstances, all of them displaying the very complex world within which social work is enacted. We feel it is important to stress that we recognise this inherent complexity and in no way wish to minimise the very intricate tapestry of circumstances within which each case occurred. In fact, it is this complexity that we seek to untangle or begin to untangle and we wonder whether the general dearth of research on the issue of misconduct in social work is due, in some part, to the difficulty in finding a research entry route into this topic.

We are aware that our literature review and small-scale study suffered from limitations of resources and that our efforts have done little to progress any new knowledge on social work misconduct including the factors that influence it. However, on foot of our attempts to better understand the nature of misconduct and its relationship with professional regulation, we are even more convinced that it is a concept in need of exploration and theorisation. Our main conclusion, based on our work to date, is that, without a stronger evidence base and a more rigorous debate and reflection within the profession on the issue of misconduct specifically, and fitness to practise more generally, and even regulation itself, practitioners, employers, 
educators, students and regulators will continue to try to deal with this issue constrained by a theoretical and research deficit.

\section{References}

Banks, S. (2010) 'Integrity in professional life: Issues of conduct, commitment and capacity', British Journal of Social Work, 40(7), pp. 2168-84.

Boland-Prom, K. W. (2009) 'Results from a national study of social workers sanctioned by state licensing boards', Social Work, 54(4), pp. 351-60.

Clark, C. (2006) 'Moral character in social work', British Journal of Social Work, 36(1), pp. $75-89$.

CORU (2011) 'CORU announces opening of Social Worker's Register', available online at http://www.coru.ie/en/news/details/opening_of_the_social_workers_register_31_may_2011 (accessed on 21 January 2015).

Council for Healthcare Regulatory Excellence (2009) Handling Complaints: Sharing the Registrant's Response with the Complainant, London, Council for Healthcare Regulatory Excellence, available online at https://www.professionalstandards.org.uk/ docs/default-source/psa-library/chre-report-on-sharing-the-registrant's-response.pdf? sfvrsn=0. (accessed on 21 January 2015)

Currer, C. (2009) 'Assessing student social workers' professional suitability: Comparing university procedures in England', British Journal of Social Work, 39(8), pp. 1481-98.

Dickens, J. (2010) Social Work and Social Policy: An Introduction, London, Routledge.

Dillon, J. (2007) 'The conundrum of balancing widening participation with the selection of suitable students for social work education', Social Work Education, 26(8), pp. 827-41.

Furness, S. (2013) 'Conduct matters: The regulation of social work in England', British Journal of Social Work Advance Access published November 12, 2013, doi:10.1093/ bjsw/bct178.

Holmström, C. (2014) 'Suitability for professional practice: Assessing and developing moral character in social work education', Social Work Education, 33(4), pp. 451-68.

Jack, G. and Donnellan, H. (2010) 'Recognising the person within the developing professional: Tracking the early careers of newly qualified child care social workers in three local authorities in England', Social Work Education, 29(3), pp. 305-18.

Koornneef, E. (2008) The Introduction of Social Regulation for Health and Social Services in Ireland: A Review of the Literature, Dublin, Ireland, Centre for Nonprofit Management, School of Business, Trinity College Dublin, available online at https://cnm.tcd .ie/assets/pdf/resource-library/2008/koornneefe.pdf (accessed on 22 January 2015).

McCann, C. W. and Cutler, J. P. (1979) 'Ethics and the alleged unethical', Social Work, 24(1), pp. 5-8.

McKenna, K., Day, L. and Munro, E. (2012) Safeguarding in the Workplace: What Are the Lessons to Be Learned from Cases Referred to the Independent Safeguarding Authority?, Independent Safeguarding Authority, available online at http://dera.ioe. ac.uk/15910/1/1ISA\%20Research\%20Report\%20Ver\%203-11.pdf (accessed on 21 January 2015).

McLaughlin, K. (2007) 'Regulation and risk in social work: The General Social Care Council and the Social Care Register in context', British Journal of Social Work, 37(7), pp. 1263-77. 
Nathanson, I. L., Giffords, E. D. and Claderon, O. (2011) 'Expanding awareness: Issues in the development of an ethics scale for the social work profession', Journal of Social Work Education, 47(1), pp. 133-49.

National Association of Social Workers (1995) Overview of a Decade of Adjudication, Washington, DC, National Association of Social Workers.

Selznick, P. (1985) 'Focusing organisational research on regulation', in R. Noll (ed.), Regulatory Policy and the Social Sciences, Berkeley, University of California Press.

Strom-Gottfried, K. (1999) 'Professional Boundaries: An Analysis of Violations by Social Workers', Families in Society: The Journal of Contemporary Human Services, 80(5), pp. 439-49.

Strom-Gottfried, K. (2003) 'Understanding adjudication: Origins, targets, and outcomes of ethics complaints', Social Work, 48(1), pp. 85-94.

van Heugten, K. (2011) 'Registration and social work education: A golden opportunity or a Trojan horse?', Journal of Social Work Practice, 11(2), pp. 174-90.

Walshe, K. (2007) 'Understanding what works - and why - in quality improvement: The need for theory-driven evaluation', International Journal for Quality in Health Care, 19(2), pp. 57-9.

Walshe, K. (2009) 'The effectiveness of healthcare regulation: Lessons from research', presentation delivered at the 7th EPSO Conference, Cork, Ireland, 15 May 2009, available online at http://epsonet.eu/mediapool/72/723588/data/The effectiveness_of_healthcare_regulation_lessons_from_research_by_Kieran_Walshe.ppt\#339, 57,Conclusions (accessed on 21 January 2015). 